\title{
Characteristic of stationary phases for gas chromatography
}

\author{
(C) Andrey Y. Kholin, Elena E. Finkelshtein, and Svetlana V. Kurbatova** \\ Department of Physical Chemistry and Chromatography. Samara National Research University. \\ Acad.Pavlova St., 1. Samara, 443011.Russia.Fax: +7 (846)334-54-17. E-mail: curbatsv@gmail.com
}

\begin{abstract}
*Supervising author; ${ }^{+}$Corresponding author
Keywords: gas-liquid chromatography, stationary phases, chromatographic polarity, polarity factors, choice of stationary phases, Rorschneider, Mac-Reynolds, Laffort systems.
\end{abstract}

Abstract
The methods of preferred stationary phases choosing the used in gas-liquid chromatography are analyzed. It is shown that in the literature, such criteria as selectivity, sorption capacity, thermal stability, reproducibility of properties, operating temperature range, etc. are used as criteria for choosing suitable stationary phases. One of the most used methods for characterizing stationary phases is their classification using chromatographic polarity based predominantly on the values of polarity factors proposed by Rorschneider and Mc Reynolds. The basis of these systems is the characterization of various types of intermolecular interactions into which stationary phases can enter, using a set of standard substances. The system of Rorschneider-McReynolds polarity factors is also the basis of the spectral approach to identifying the components of complex mixtures, the essence of which is to use the combination of physicochemical characteristics of the sorbate and sorbent, which allows to establish the structure of sorbate molecules based on their different ability to be sorbed by stationary phases of different chemical nature. The spectral approach is applied to the characterization of weakly polar stationary phases of various chemical nature. It was shown that despite the close chromatographic polarity of the stationary phases, the retention of substances belonging to different classes of compounds can significantly differ and be determined by the values of descriptors characterizing the types of intermolecular interactions and the tendency of the stationary phases to a certain type. Spectra of 5 stationary phases obtained using the Rorschneider, Mac-Reynolds, and Lafffort solubility factors are presented. It was established that the possibility of preferential retention of sorbates of various chemical nature is determined by the ratio between the values of these descriptors. The possibility of choosing the corresponding stationary phases for the selective separation of sorbates of various chemical nature is shown.

\section{References}

[1] K.A. Holbert, M.S. Wigderhaus. Introduction to gas chromatography. Moscow: Chemistry. 1990. 352p. (russian)

[2] E.A. Zaitseva, A.M. Dolgonosov. Sorption and chromatograph. Processes. 2019. Vol.19. No.5. P.525541. (russian)

[3] A.M. Dolgonosov, O.B. Rudakov, A.G. Prudkovsky. Column analytical chromatography: practice, theory, modeling. St. Petersburg: Lan. 2015. 468p. ISBN: 978-58114-1870-1 (russian)

[4] L. Rohrschneider. J. Chomatogr. A. 1965. Vol.17. P.1-12.

[5] W.O. McReynolds. J. Chromatogr. A. 1970. Vol.8. P.337-345.

[6] J. Franc, S. Michailova. J. Chromatogr. 1963. Vol.12. No.1. P.22-31.

[7] M.S. Wigdergauz, L.V. Semenchenko, V.A. Ezrets, Yu.N. Bogoslovsky. Qualitative gas chromatographic analysis. Moscow: Science. 1978. 244p. (russian)

[8] P. Laffort, F. Patte. J. Chromatogr. 1987. Vol.406. P.51-74.

[9] K.K. Konstantinova, S.V. Kurbatova, V.G. Berezkin, E.E. Finkelstein. Zhurn. Appl. Chemistry. 2005. Vol.78. No.8. P.1522-1526. (russian)

[10] K.K. Konstantinova. Physico-chemical laws of retention of adamantane derivatives in high performance gas chromatography. Abstract. Cand. Chem. sciences. Saratov. 2006. 22p. (russian)

[11] R.V. Golovnya, T.A. Misharina. Izv. RAS Ser. chem. 1996. No.8. P.2033-2038. (russian)

[12] M.H. Abraham, A. Ibrahim, A.M. Zissimos. J. Chromatogr. A. 2004. Vol.1037. P.29-47.

[13] G.V. Lisichkin, A.Yu. Fadeev, A.A. Serdan, P.N. Nesterenko. Chemistry of grafted surface compounds. Moscow: FIZMATLIT. 2003. 592p. (russian)

[14] S.V. Kurbatova, E.A. Kolosova, M.S. Wigdergauz. Zhurn. Phys. chemistry. 1993. Vol.67. No.4. P.833836. (russian) 